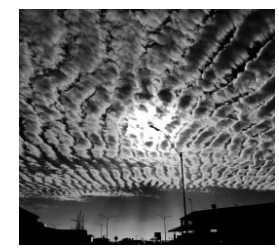

\title{
Poetic resistance: Karen long- distance nationalism, rap music, and YouTube
}

\section{Charlotte Hill}

Goldsmiths University of London, UK

\begin{abstract}
This article investigates a concern among encamped elder Karen refugees (an ethnic minority from Myanmar) living along the Thai-Myanmar border that the youth are disconnected politically and culturally. I argue that Karen youth are creative, active participants, reimagining and revitalising Karen politics and culture in their image. I explore how displaced youths have found a voice in Karen rap and how they express this voice in the digitally mediated lived space of YouTube. I consider YouTube as a lived space where citizenship is reimagined and long-distance nationalism is articulated. Finally, I contend that YouTube is transforming Karen youths' political experiences and mobility and that they are actively political - just not in the way the elders expect.
\end{abstract}

\section{Keywords}

digitally mediated spaces, Karen refugees, long-distance nationalism, rap music, refugee camp, youth politics, YouTube

\section{A space of political and creative expression}

In among an abundance of flowers and shrubs, we sit around a concrete table under the shade of a large tree. The tranquillity of Saw Ka Lu's fenced garden seems a million miles away from the oft-challenging environment of the camp. However, his house and garden are right in the middle of Mae La Temporary Shelter, a refugee camp with a population of over 34,000 inhabitants (UNHCR, 2020), located on the Thai-Myanmar border. Since 2008, Saw Ka Lu and his musician brother have provided a safe space for artistic expression (Figure 1). From humble beginnings 13 years ago, the brothers have grown a

\footnotetext{
Corresponding author:

Charlotte Hill, Goldsmiths, Media, Communications and Cultural Studies, University of London, 8 Lewisham Way, New Cross, London, SEI4 6NW, UK.

Email: chill004@gold.ac.uk
} 


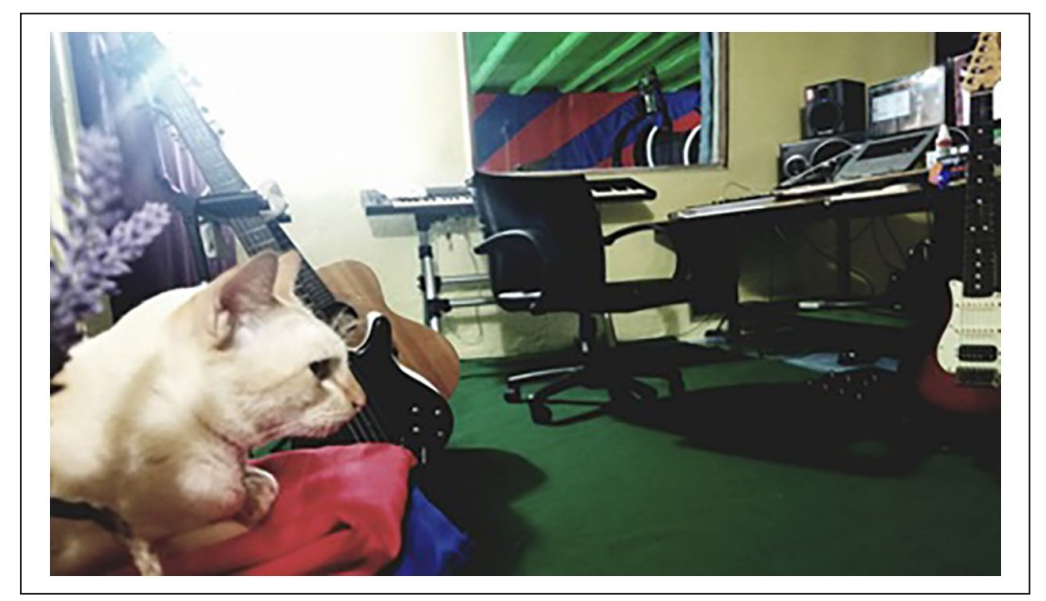

Figure I. Recording studio, Mae La Refugee Camp.

Source: Photo by Saw Ka Lu.

successful recording studio and business within the camp. In the early days, they could not afford a 'mic or accessories', so they borrowed them from a local church. By fixing an old mixer and covering their bamboo walls with blankets, they started to record music for fun; 'people liked what we were doing, and with their support, we were able to build a better studio', he says.

Unlike the desperate image of the refugee camp as a bounded space of exception (Agamben, 2005) depicted in the media and by non-governmental organizations (NGOs), the camps along the Thai-Myanmar border are bursting with artistic and cultural expression. The vivid presence of music underpins daily life, which was evident in each visit I made to Mae La camp (Mae La going forward). Yet, according to a report carried out by the UNHCR, an overlooked area of research is artistic activities and expressions (Andemicael, 2011: 1), an area I intend to explore further in this article.

In the camp, elders expressed the belief that the youth were no longer dedicated to the fight for self-determination and a free Karen State. 'The youth in the camp are connected' digitally, an elder tells me:

On special Karen days, they watch what is happening live on their small screens or see the Karen media cover internal events [in the Karen State] but what I see is a disconnect because they are not there. They don't take it seriously. They don't see and respect their national heroes. There is no feeling at all.

Considering these concerns, this article explores how displaced Karen youths articulate their political agency through rap music production. With a specific focus on transnational cultural flows and digitally mediated space (DMS), I argue that the confluence of rap and YouTube enables young Karen to re-work a certain kind of Karen-ness and export it to a global Karen diaspora. I explore how YouTube becomes a lived place where citizenship and belonging are reimagined. 
Many scholars have written on Karen nationalism and identity (Cheesman, 2002; Harriden, 2002; MacLachlan, 2012; Rajah, 2002; Sharples, 2017; South, 2009). Yet no study has attempted to explore how young displaced Karen demonstrate political agency and resistance to their ongoing situation through the medium of rap and DMS. Gillespie et al. (2018: 1) note that most studies on forced migration are 'yet to consider the increasingly important role of the digital in transforming refugee experiences and mobilities'. To explore this under-researched area, this study will consider YouTube as a DMS transforming young Karen refugees' political experiences and mobility, and will argue that Karen youths are actively political.

I will first discuss how I approach DMS as a lived place. The significance I assert lies in the notion of presence. Drawing from Steuer (1992), I refer to presence as having a sense of being in an environment. Steuer (1992: 75) invites us to think beyond our physical surroundings, stating:

When perception is mediated by a communication technology, one is forced to perceive two separate environments simultaneously: the physical environment in which one is actually present, and the environment presented via the medium.

When considering two separate environments, the 'lived' physical space such as a refugee camp and the digitally mediated one simultaneously, we can explore how they coexist in the everyday and 'contribute to meaningful social and subjective relations' (Twigt, 2019: 174). I argue that YouTube can be viewed as a lived place, especially when physical mobility and offline life are extremely restricted. In situations where people are classified as refugees or stateless, participation in politics and self-determination is challenging; thus DMS offers an environment where individual and collective voices can express themselves (Martiniello and Lafleur, 2008). DMS presents different affordances which may facilitate and shape discussion networks (Halpern and Gibbs, 2013: 1160). Recognising that affordances are not simply the architecture or design features of a space, I subscribe to Gibson's (1977: 68) concept of what an environment offers us and thus take a socio-technical approach.

YouTube represents a 'portal to communities' where youth bond, engage with public discourse and explore identities (Chau, 2010: 65). Affordances such as low entry requirements and participant anonymity makes YouTube an ideal space for my participants to live within - as long as they have the means to access it, of course. It is a space where creators can collaborate with others by joining accounts while connecting with their subscribers who are not in their immediate physical space. The more the creator produces, the more rewards they achieve for their content. Burgess and Green (2009) state that video and visual content have long been primary vehicles of social interaction and communication. YouTube facilitates social interaction and communication by transcending physical borders. However, to avoid being technologically deterministic, I acknowledge that participants must first have access to technology and the internet. Then they must have a level of technological literacy to engage with content. Coerced mobility (Cabalquinto, 2018; Sheller, 2018; Sheller and Urry, 2000) is a further concern; participants, due to their physically restricted situation, have no choice but to use technology and DMS to compensate for physical distance, separation and absence. 


\section{Citizenship beyond the state}

Agamben $(1998,2005)$ focused his thoughts on the Greek meaning for 'life'. He makes a distinction between zoe , meaning living common to all living things (the body, reproductive life, the animal) and bios meaning the political life (the mind, political ideas, and participation). He argues that the state 'system' constitutes what is included (bios) and what is excluded (zō) and thus reduces the individual to 'bare life'. At bare life, individuals are metaphorically 'stripped bare' and therefore excluded from and placed outside the legal and political framework. I maintain, however, that camps are creative spaces where artists exercise their political voices in ways that are hardly 'bare life'.

As separated citizens connect through digital networks, the flow of information and diversity of opinion increases (Halpern and Gibbs, 2013: 1159). Diversity of opinion extends to the political, where participation and voicing one's political views, especially for disenfranchised, displaced youths, are essential components to citizenship (Literat and Kligler-Vilenchik, 2019: 1989); demonstrating how everyday offline and online lives intertwine, Burgess and Green (2009) claim that, through digital technology and DMS, everyday creative practices situated in history and the private space are remediated as public culture. Participation, of course, takes many forms; as teens become active producers of content, a participatory culture develops (Jenkins, 2009).

Participatory culture is defined as, 'a culture with relatively low barriers to artistic expression and civic engagement, strong support for creating and sharing one's creations' (Jenkins, 2009: 3). Significant to this research is the notion that the participant's voice and contribution matters and that there is a feeling of social connection and engagement with other members of the same community (Jenkins, 2009: 3). Subscribing to the notion that connection can transcend the physical, I contend that there is a juxtaposition between Anderson's (2006) imagined communities and how print capitalism was implicated in creating and maintaining long-distance nationalism and national imaginaries (Anderson, 1992; Schiller, 2005), and how new media technologies and YouTube allow young Karen to disseminate a certain kind of national identity expressed through the genre of rap.

Moving beyond Agamben's (1998, 2005) notion of citizenship, Burgess and Green (2009: 77) illuminate that citizenship refers not only to legal obligations to the state but 'how individuals participate in practices and collectives'. Citizenship is reimagined by the emergence of new political spaces; the confluences of global flows, according to Ong (2006: 697), are 'forming new spaces and entanglements of possibilities', which, in turn, 'have a mutating effect on citizenship'.

\section{Music, protest, resistance}

Ethnomusicologists have advocated for the importance of the role music plays in constructing individual and collective identities (Frith, 1996; Nettl, 1983; Russell, 2011; Slobin, 2012; Stokes, 2012; Waters and Philhour, 2019). Frith (1996: 110-11) illuminates that music is key to identities as it offers 'a sense of both self and others, of the subjective in the collective'. He emphasises that 'making music isn't a way of expressing ideas; it is a way of living them' (1996: 110-11). Likewise, Russell (2011) states that 
music provides a framework to express historical memory. Of course, not all music is political; however, focusing on group identity, historical memory, and a way of living ideas, it is beneficial to this study to draw from the subversive sounds of hip-hop culture and rap music to unpack these themes.

Leach (2008: 10) highlights that there is confusion over the terms hip-hop and rap even among the most knowledgeable musicologists. The most common view is that 'hiphop is a cultural movement' and rap 'is one of its four primary elements'. Starting as a political and oppositional art form, it became the voice of Afro-Americans (Ben Moussa, 2019: 1045) in the South Bronx, New York City, during the 1970s. These defiant political messages fluidly cross borders where hip-hop culture is embraced by marginalised groups and reimagined in their image.

\section{Methodological considerations}

Working within a refugee camp context presented many ethical questions which required continuous reflection. The guidelines set out by the Association of Internet Researchers (AoIR) stipulate that 'cross-cultural awareness is required when internet research projects involve diverse national and cultural backgrounds' (franzke et al., 2020) and researcher positionality and best ethical practice must also be considered. This research stems from a much larger ethnographic study of encamped refugees where I have built relationships with the Karen community over 12 years of living and working in Thailand and along the Thai-Myanmar border. To gain further insight into Karen cultural practices, I sought advice and support from Karen academics and community leaders, NGO workers and Karen Refugee Committee members.

Accountability, responsibility, trust and transparency are critical elements of best research practices, especially when working with vulnerable people. Reflecting on these factors, I acknowledged the responsibility to protect participant identities but without losing the integrity of the research and the voices presented. Participants who took part in the face-to-face study were fully aware of the research purpose and gave full consent. I informed them I would anonymise their names which raised an important ethical dilemma that I had not anticipated. When an individual or group has been forcefully displaced and separated from their community, often the only things they perceive they have left are their stories and experiences but, most importantly, their names. It was common for my participants to ask for their real names to be used in full. To navigate the tension between duty of care and recognition, I agreed to use either their nickname or, in instances where the participant insisted, I used their online name.

I chose a multimodal discourse analysis (MMDA) approach, as it combines interviews, text and images, and the meanings conveyed therein. The benefit of using MMDA as a tool for analysing uploaded music to YouTube is that it can 'provide insight into the relation of the meanings of a community and its semiotic manifestations' (Kress, 2012: 37); the limitation is the interruptive nature which is subjective. In the case of using video material such as screenshots, I chose to pixelate the faces. Besides the face-to-face interviews and screenshots, I drew from the online comments and reactions to the songs. This presented a huge opportunity to explore user-generated content, rich, invaluable information on the everyday lives of Karen youths. This, however, raised 
further contextual challenges around the debate over public vs private data and ethical decision-making on how these comments should be treated. Here I draw from Reilly's (2014) research on YouTube political commentary. He argues that videos (and comments) could be considered open text. Taking precautions when dealing with sensitive material, he advises researchers to anonymise the dataset and paraphrase the comments, which I have done.

The researcher within the research must also be discussed. As Fine (1994: 72) states: 'Despite denials, qualitative researchers are always implicated at the hyphen.' I have been critical of my relationship and the power dynamics with the community throughout the larger ethnographic study and reflected on the information presented in this article. I advocate that any approach other than an ethnographic one would not have elicited the respect and sensitivity needed within this fieldsite and open a space to engage with young Karen artists. Ethnography allowed me to build relationships slowly over time so that I could explore what the Karen actually do, opposed to what they say they do.

\section{New Karen poetry and political engagement}

Over the years, Saw Ka Lu has seen a decrease in female singers coming to the studio: 'Perhaps it's due to the trend in music; nowadays it's mostly hip-hop and rap,' he reasons. He claims that the youths like to sing about love and romance; however, they get more attention and support from the global Karen community if they focus on nationalism. The internet has become more affordable in the camps due to privately Thai-run telecommunication companies in recent years. As a result, Saw Ka Lu's recording studio in Mae La has seen an increase in popularity. Highlighting the genderedness of the phenomenon, his new clients, the majority of whom are young men, see the potential participation and visibility that YouTube offers. In what follows I illustrate how YouTube plays a substantive role in disseminating Karen national messages while providing a space to build networks and articulate political agency.

According to Saw Ka Lu, the shift in musical taste is due to access to media, notably YouTube. Mobile phone coverage and the internet has been widespread in Mae La since 2008. Similarly, people connect through private data plans in Mae Ra Moe camp, although they claim the coverage is often precarious. For those who can afford one, a smartphone and the internet offers a portal to a space where the youths can participate and connect with others in the wider diaspora. I assert that YouTube provides the Karen youth with a platform to be seen (Marwick, 2012). It also exposes them to global musical influences, in this case, hip-hop culture and rap music, which they embrace and make their own.

Engaging with international music has not always been possible across the border in Myanmar. Under the military regime, musicians and songwriters were silenced with strict censorship laws and violence (Zaw, 2004). Under the regime, the music industry suffered significantly both economically and technologically (Zin, 2002). Before 2010, less than 0.3 per cent of Myanmar citizens had access to the internet (Shadrach, 2018). In 2016 'only $30 \%$ of the population had ever used the Internet despite a $78 \%$ smartphone market penetration' (Leong, 2020: 100). In 2017, the Myanmar government estimated that there were over 10 million active internet users. They further claimed that 
$80-90 \%$ of the population had access to the internet (Valdovinos Kaye and Myint, 2021). The mobile and internet landscape significantly changed in 2021, after the military staged a successful coup. On 6th and 7th February 2021, the junta blocked the internet. Furthermore, mobile operators and internet service providers were ordered to suspend social media platforms temporarily. In May 2021, telecommunication corporation Telenor claimed their network functionality was fully restored; however, stable access to the internet remains precarious (LRWC, 2021; Telenor, 2021).

With history repeating itself, it is not surprising that hip-hop culture and rap music, with its mobilising power, have become popular with the Karen youth. As Safieh (2013: 71) states: 'Hip-hop, as a culturally mobile genre of music, is constantly being redefined and reinterpreted as it is appropriated by various different ethnicities and nationalities around the world'. Rap's subversive nature and rebellious creativity have provided a space for new Karen rebels to articulate long-distance nationalism. Through politically charged lyrics created in the camp, youths blend Karen languages, cultural symbols and traditional Karen musical influences with rap; the results are new rebel anthems that speak of Karen revolution and belonging, persecution and oppression.

Challenging the elders' belief that the youths are disconnected politically, I observe two main areas of focus within the three songs featured in this article. The first of these is what they perceive as a continuous fight against the Tatmadaw's (Myanmar Army) oppression and persecution, resulting in family separation and displacement from Kawthoolei - the Karen imagined homeland. Self-determination, ethnic recognition and the fight for Kawthoolei are recurrent themes in Karen youth music presented on YouTube. These themes, I argue, come from a strong historical foundation found in Karen Hta song-poetry. This oral tradition of song poems expresses Karen history and the fight for autonomy (Zin, 2000). It articulates guilt and belonging in exile (Cho, 2013). Hta historically is performed at ceremonies or at home and in the community; although the elders are not witnessing Hta in the traditional sense, this oral tradition, I argue, is indeed still being carried on, just in the DMS of YouTube.

The second focus acknowledges themes around Karen diversity and the volatile relationship between the different Karen groups. Here the youth sing about historical intergroup fighting, the need for unity, and the struggle for peace. The artists draw from historical figures of symbolic significance, folklore, and images of national importance. Each song uploaded to YouTube attracts an audience of like-minded individuals who, in turn, participate in supporting the song's narrative. Affordances such as liking, sharing, and commenting on the videos allow the youths, often geographically isolated, to connect and maintain networks with other Karen in the wider diaspora. It also encourages the artists to produce similar content as it reaffirms their visibility.

\section{'Revolution' (Tempered Family, 2020)}

Released in August 2020, 'Revolution' has been viewed, as of April 2021, over 310,000 times. Tempered Family consists of seven members and, as the name suggests, their music combines powerful, angry tones with lyrics calling for resistance, togetherness, forgiveness, and unity. Describing the meaning behind the name, Real 9ine states: 'The Karen are a family, and this is expressed in our name, we are all the same, we are one 
family. Although we are young and we might be short-tempered, we mean it in a good way.' Real 9ine was born in Mae Ra Moe refugee camp and moved to Mae La when he was five. After finishing his schooling, he had the opportunity to study at a migrant school in the Thai border town of Mae Sot. At the age of 25, he is now living and studying at a university in the north of Thailand. He understands how fortunate he is to have had the opportunity to leave the camp but says it was in his formative years growing up in the camps that shaped his ideas and he still returns to produce songs in Saw Ka Lu's studio. Although Real 9ine can produce his work outside the camp, he demonstrates that the camp for him is an artistic sanctuary that fuels his creative political freedom. He is allowed to be Karen, stating that he can speak his own language, join cultural events and traditions and wear Karen clothes. Believing there are many ways to show resistance and a political voice, he states:

I totally disagree that the youths are not political. Politics is not just about sitting around a table or holding a gun. We can start a revolution through our music. We are musical revolutionists. We can inspire people in our own way.

Real 9ine, however, has no intention of becoming a politician or a soldier. Through the medium of rap and YouTube, he believes he can share his message faster, suggesting political participation extends his physical presence and transcends borders. Here, he can produce personally meaningful media and contribute to a broader discussion on the future of the Karen people.

Connection to the wider diaspora is essential: 'We can be political in a unique way. Rap gains us more attention, and YouTube help's spread our message faster. Our fans are all over the world.' The artists can speak directly to their global audience in the comments section. The more they produce and upload, the more engagement they have with fans who, over time, expect more political contributions from the group. As boyd (2014: 13) points out, 'social media alters and amplifies social situations . . . they help create new social dynamics'. Tempered Family are creating a new social and political dynamic away from the traditional political scene. One which reaches and is heard by a vast number of young Karen within Myanmar, in the camps, and the wider diaspora. They are also creating a new form of citizenship through the flows of transnational shared Karen practices, interests, identities and concerns. As Ong (2006: 499) states, there are mutations in citizenship beyond the traditional national terrain or an Agambenian perspective. The space of these new global assemblages become the 'site for political mobilisations by diverse groups in motion', thereby 'moving beyond the citizenship-versus-statelessness model'.

Fans of the group leave validating comments on their channel in Karen, Thai and English. These messages indicate how important this song is to Karen youths and shows the visibility and spreadability of the music and how long-distance nationalism (Anderson, 1992) is articulated. Long-distance nationalism is described as 'a set of identity claims and practices that connect people living in various geographical locations to a specific territory that they see as their ancestral home' (Schiller, 2005: 570). Longdistance nationalists 'are expected to maintain some kind of loyalty to the homeland' (Schiller, 2005: 571) and support its struggle in whatever way is required. As Cho (2011: 
207) asserts, the Karen in Auckland have formed collective solidarity with a wider global community by listening to Karen music and reading in their languages. The internet and social media, she states, is used to maintain ties with those in Myanmar and the borderlands - in camps such as Mae La - which in turn, keeps 'them up-to-date', sustaining 'their identity and actions as activists'. Significantly, there are parallels here with Anderson's (2006 [1983]: 6) imagined national community and one built and maintained on YouTube. As Anderson suggests, 'members of even the smallest nation will never know most of their fellow-members . . . yet in the minds of each lives the image of their communion'. Print capitalism, according to Anderson (2006 [1983]), allowed for a common discourse and nationalism to emerge. Likewise, the Karen youths are using YouTube to connect and be kept up-to-date with current national discourses. The difference is they are now able to speak to one another and actively do so.

'Revolution' is significant. It is a prime example of how the youths are mixing traditional Karen symbolism with modern beats: 'I don't think the older generation fully listen to our lyrics. We express ourselves a lot through music; we tell many stories', Real 9ine tells me. Law Eh Paw, an elder, claims she does not like new songs as they 'talk too much' and the lyrics are 'not beautiful'. However, 'Revolution' recalls seven decades of civil war, draws from the past, and asks, 'when will my people be united?' Calling to attention historical tradition, 'Pru Kalar' is sung, a ritual based in animism where the spirit or ' $k$ 'las' is called back to prevent it from wandering too far or being consumed by evil spirits (Marshall, 1922). In contemporary times, calling back the spirit has become an annual event in the form of the wrist-tying ceremony. Describing the importance of Pru Kalar, Real 9ine posits: 'We are asking Karen, wherever you are, come back and tie yourselves together. We need to remember our ancestors and traditions, and not only look to the modern'. Real 9ine is demonstrating how YouTube provides a space where tradition and modernity meet and where culture evolves. He is not asking Karen to come back physically but to meet and participate in solidarity by acknowledging the past within a DMS. Demonstrating how rituals and Karen symbolism are used to create solidarity and belonging, significant Karen national signs are used, such as the flag and the Kwekabaw mountain. Steeped in Karen folklore, Kwekabaw, the Mountain of Sorrow, signifies Kawthoolei. To reinforce these national signs, there is a juxtaposition between the rap about revolutionary leader Saw Ba U Gyi and their disillusionment with the National Ceasefire Agreement (NCA) - an agreement between the Myanmar government, the Tatmadaw and the Karen National Union (KNU):

Hold on to Saw Ba U Gyi's principles

We signed the NCA, we are not to be beheaded

We need genuine peace

We will govern our own country and people

We will decide our destiny, build peace, and understand each other

Then we will fight off the evil military regime. 
Saw Ba U Gyi, who was assassinated in 1949, is seen by many Karen as 'the face of the Karen rebellion' (Hornig, 2019). His four guiding principles, recited at national events, are: (1) for us, surrender is out of the question; (2) the recognition of the Karen State must be complete; (3) we shall retain our arms; and, finally (4) we shall decide our own political destiny. Although the principles were often quoted to me by the youths, there were just as many who expressed frustration and disappointment with Karen leadership and vision. Hero, for example, is a singer-songwriter; on several occasions, he spoke about his discontentment with Karen politics, choosing to write and sing about unity and forgiveness. Skywhite, a 21-year-old student, tells me that she is 'really sad' to hear that her leaders are working closely with the Burman ${ }^{1}$ and is concerned for her future. The Karen future was a recurrent theme expressed by the youths, as well as in the songs included in this article. Tempered Family look to the past when they rap about their future:

We died once; will we die over again?

Learn from the past and build the foundation of peace

Pah Wah Khee said, 'if we know that we are Karen, we will be given our country' (singing)

Be united, be united, my people, Karen people (singing).

Pah Wah Khee translates as Mr White Bone and refers to the Tatmadaw, who implied that once the Karen form a united union and stop fighting between themselves, they will own their land and gain independence.

\section{Visual symbolism}

In the accompanying music video, the opening sequence shows the group wearing bulletproof vests (Figure 2), a symbol of the ongoing Karen military conflict with the Tatmadaw. As the music starts and the group call for a Karen revolution, one artist wears full military combat uniform while crushing rocks on the side of the road with a large hammer. This 10-second clip depicts the need for Kawthoolei to develop and build a robust infrastructure. It alludes to the Karen history of slavery, where civilians were forced to labour by the Tatmadaw, and how Karen society and peace have been crushed under a dominating force (Figure 3).

In a later scene, these rocks are weaponised by the group. Reminiscent of Palestinian stone-throwing or the David and Goliath fable, this image on the one hand symbolises the disparity in power between the Tatmadaw and the ethnic minorities in Myanmar. On the other, it represents an image of repression as an image of rebellion and resistance (Figure 4).

According to Entwistle (2015: 7): 'Operating on the boundary between self and other, [dress] is the interface between the individual and the social world, the meeting place of the private and the public.' As an assertion of Karen citizenship and national identity, the group wear traditional Karen shirts along with army fatigues (Figure 5). Allman (2004: 1) 


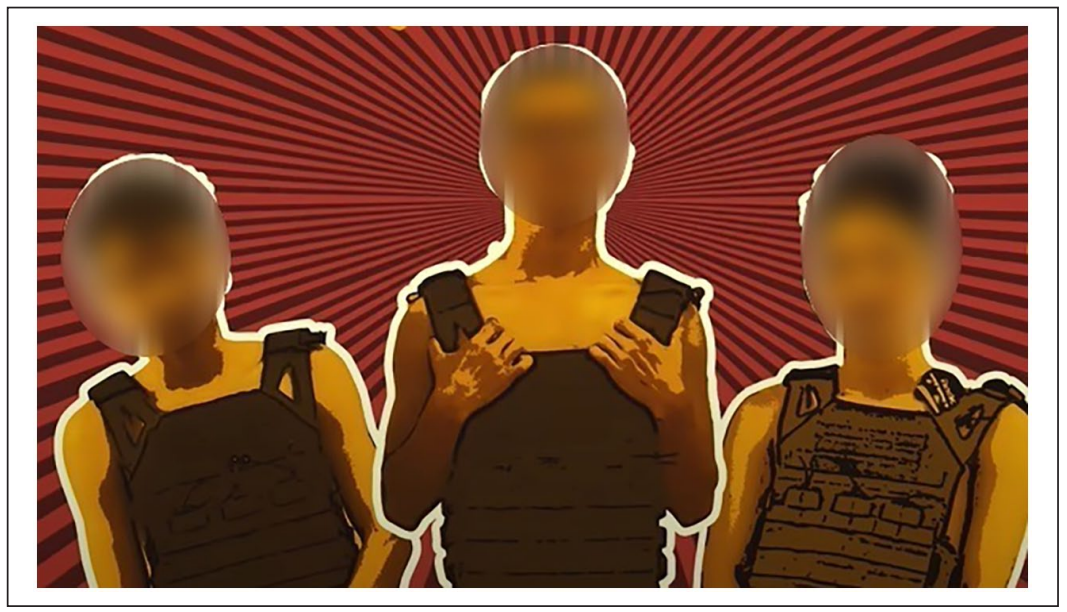

Figure 2. Opening sequence.

Source: Tempered Family, 'Revolution'.

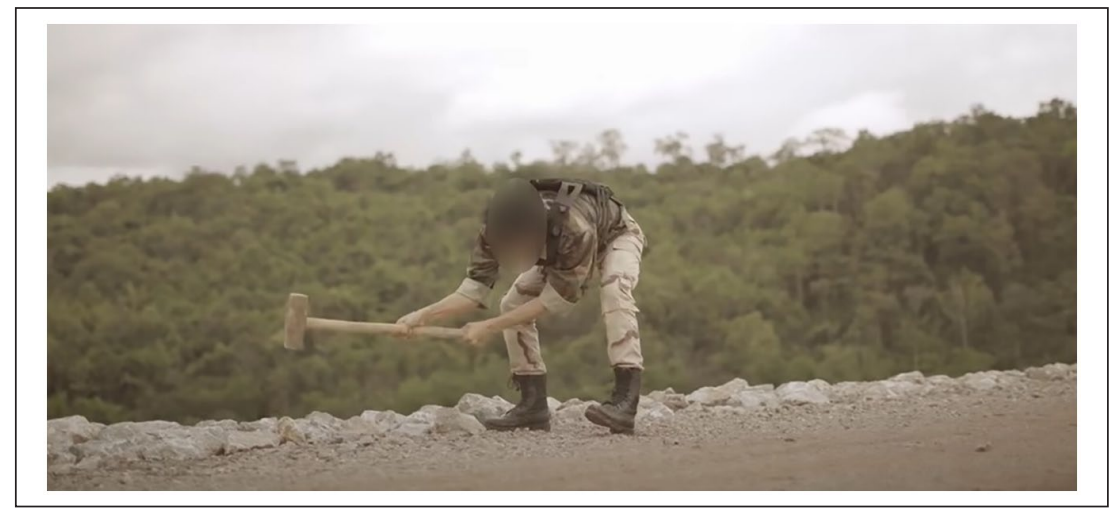

Figure 3. Desire for development and reference to forced labour.

Source: Tempered Family, 'Revolution'.

illuminates that fashion is 'an incisive political language capable of unifying, differentiating, challenging, contesting and dominating'. Under the Tatmadaw's regime and the Burmanization of the country, ethnic minorities were prohibited from speaking their languages or practising their cultures. I argue that Figure 5 articulates how resistance, politics, and long-distance nationalism are characterised and performed within the unifying collective action of wearing both the Karen shirt and the army fatigues, and singing in Karen. It also further supports the KNU's ideological approach of solidarity and sameness. As South (2009) points out, the KNU have for decades promoted a pan-Karen identity in terms of dress, dialect and custom. This is reinforced in the lyrics: 


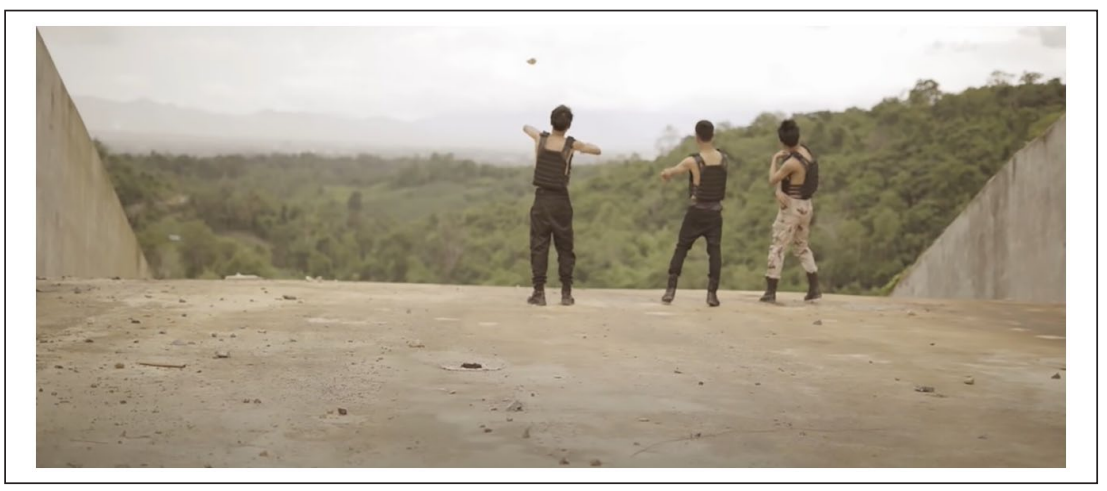

Figure 4. Image of rebellion and resistance.

Source: Tempered Family, 'Revolution'.

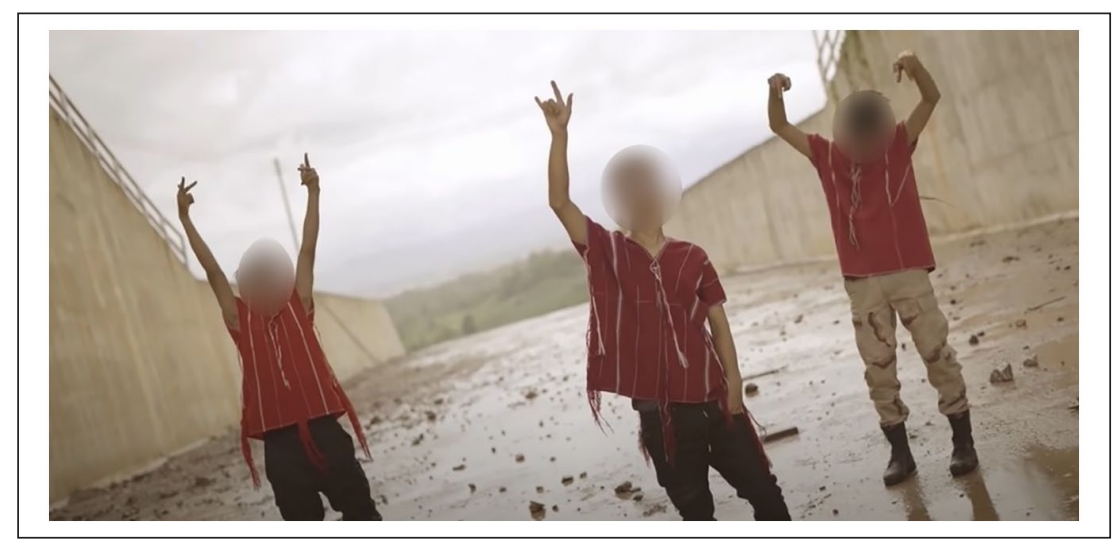

Figure 5. Articulation of Karen citizenship.

Source: Tempered Family, 'Revolution'.

Love our heritage

Love our culture

Love our language

Hold on to them, my people, my Karen people.

With such a diverse and divided population, questions arise about which heritage, culture or language Tempered Family are referring to? The following example, 'Who are you?', further explores the diversity of the Karen population and challenges the concept of sameness. 


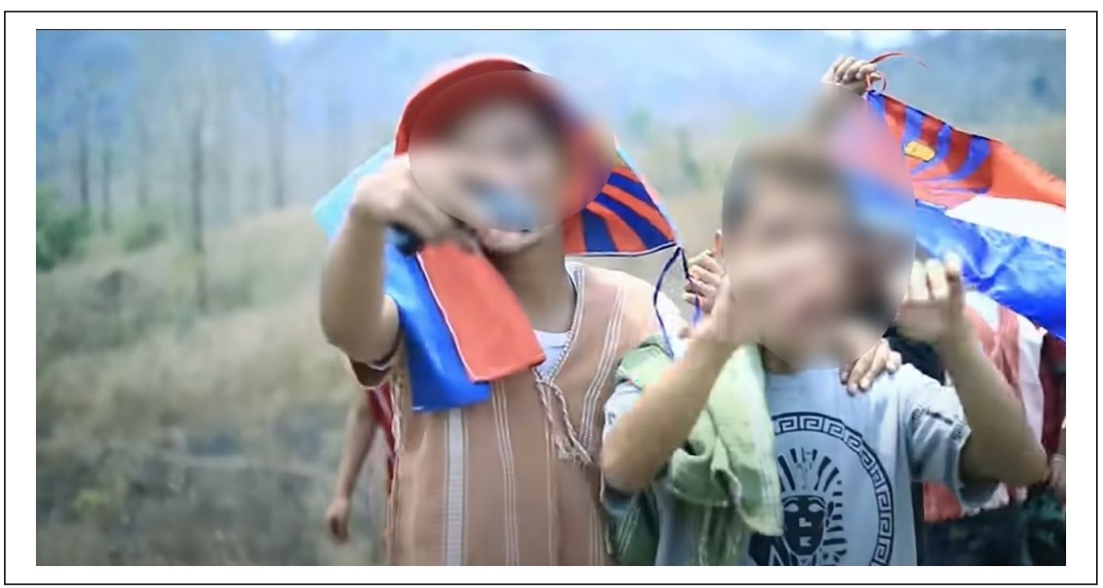

Figure 6. 'We pick up arms'. Source: TKNG, 'Who are you?'

\section{'Who are you?' (TKNG, 20I7)}

'Who are you?', released in 2017, challenges the idea of a pan-Karen identity, solidarity and belonging, and has been viewed over 1.8 million times as of April 2021. A catchy pop song that incorporates rap, the music video is filmed in the camp with the familiar Mae La mountain in the background. The song opens with the sound of the kweh, an instrument made from a water buffalo horn. Saw Ka Lu tells me that he often includes traditional Karen instruments and sounds with other musical genres - a further example of how artistic activities in the camp are nurturing cultural production. As the horn is played, members of the group, one holding the Karen flag, put on their Karen shirts over their t-shirts and jeans. One artist is seen wearing a t-shirt declaring 'ME AGAINST THE WORLD'. They challenge those who wear the Karen shirt without knowing their heritage, cultures, and languages:

\section{I dress up in Karen attire}

I call myself Karen, but where is my heart that loves the Karen

\section{Re-evaluate.}

Throughout the song, the members hold the Karen flag, a symbol of togetherness, unity, and nation. Through images seen on YouTube, the flag further reminds the rest of the world, particularly Myanmar, of the Karen historical past, its political present, and the imagined independent future. It is a call to all Karen separated by war to mobilise and fight for the nation. Watching the music video with Saw Ka Lu, I notice one artist holding a gun (Figure 6). 
Nonchalantly Saw Ka Lu says, 'Yeah, but it's not a real one'. Acknowledging that music is more than just lyrical (Baily and Collyer, 2006), meaning is made by incorporating cultural and political artefacts into both the music and video. The gun is a representation of conflict, a sign of violence and resistance. By incorporating other artefacts such as the flag, the group are articulating political agency, empowerment, and citizenship, along with a declaration of resistance to past and present realities. Yet it is within the lyrics that the presence of the gun is made more explicit:

I pick up arms

I say I fight for my people

In which direction are my weapons pointed

Re-evaluate.

Like the themes in 'Revolution' (Tempered Family, 2020), they are referencing the ongoing civil war and the internal conflict between the different Karen armed groups. Unlike in 'Revolution', 'Who are you?' highlights the diverse population and internal division:

We have different religions

We have different dialects, but our fate is the same

Re-evaluate.

As a call to action, they refer to Saw Ba U Gyi's four principles and draw from their ancestors' words: 'Our elders say: We will be magical only when we are united.' It is in the DMS of YouTube that the elders' words are realised. According to Real 9ine, all Karen worldwide are their audience. However, his imagined community reaches far further. An example of their reach is located in comments left from non-Karen followers who leave reaffirming positive comments. One participant indicates they are ethnically Karenni, born in a camp along the Thai-Myanmar border. They now live in Minnesota, where many Karen and Karenni have resettled through the UN resettlement programme. This participant exemplifies how YouTube has provided a space for them to connect. It facilitates a space to articulate belonging from a distance and between ethnic groups. Hermes (2006) describes the forging of new bonds between publics as cultural citizenship whereby the public is constituted, politically and socially in places other than the traditional political sphere. A Thai living in the Netherlands leaves another comment of support, stating she is just a normal Thai woman who loves their music - reaffirming how music transcends borders, cultural differences, and languages. Through the affordances of YouTube, the group's message reaches a much larger and more diverse audience. The final example, 'Life in MRM refugee camp', focuses on how encamped young Karen perceive themselves and their current situation. 


\section{'Life in MRM refugee camp' (NUCELER and OBED 7, 2020)}

'We are Karen; it's important to keep our identity and dignity', Saw Na tells me. MRM stands for Mae Ra Moe camp. The camp is situated 4 kilometres from the Thai-Myanmar border in the mountainous Mae Hong Son region in northern Thailand. Saw Na, the writer and producer of the song, came to the camp as a baby 25 years ago, when the camp first opened. When the KNU's headquarters fell in 1995 (The Border Consortium, 2020), families such as Saw $\mathrm{Na}$ 's fled the escalating violence and crossed the border into Thailand.

Describing his motivation to write the song as a way to narrate everyday life and encamped experiences, Saw Na states: 'We have suffered here for 25 years. The space in the camp has become very tight, it's like living in prison, and we feel we have lost our human rights.' With a focus on everyday life, Saw Na weaves lyrics such as 'because of the tension and fighting, our Karen people are displaced and lost', a reference to the ongoing fighting between the Tatmadaw and the Karen National Liberation Army, with the tension of 'living under other's control' and the continued struggle with ration cuts and mental health issues such as depression. As a stateless person, Saw $\mathrm{Na}$ feels helpless and stuck, yet by uploading his music to YouTube, his mobility and presence transcend his physical restrictions as he reaches out to connect with others.

According to Saw $\mathrm{Ka} \mathrm{Lu}$, music and the internet are often the only way encamped youths can leave the camps. Saw $\mathrm{Na}$ agrees that the youth are disconnected but not in the same way the older generation view them: 'We have a lot to say, but you cannot challenge the elders. Elders say we are not political, but we are - they are wrong, we know our history, I do not accept this point of view.' Not able to challenge the elders or express his political voice and agency within the Karen society due to deeply ingrained cultural respect for elders and social rules, Saw $\mathrm{Na}$ has turned to YouTube to participate. Inspired by Karen heritage and the stories he has made from his experiences within the camp, his song blends a traditional instrumental sound at the start of the track with a more conventional hip-hop beat. He does, however, highlight the difficulty with maintaining Karen culture in the camp: 'I wanted to use traditional Karen instruments, but I couldn't find any in the camp, so I found something similar on my keyboard. I think it might sound more Chinese, though.' His comment illustrates how young Karen are becoming culturally disconnected and how digital media allows for a hybridity of cultures. Although Saw Na has actively tried to source Karen instruments, he was forced to replace them with a 'Chinese sound'. This further raises questions about the role of digitised sounds and how the act of playing an instrument may be reimagined. On the one hand, why would the youths need to learn a traditional Karen instrument if they can one day replicate it on a keyboard? It is not just the sound, as demonstrated by Saw $\mathrm{Na}$, that is important but the lost cultural knowledge and ecosystem. The significance lies within the youths' determination to create cultural production and revitalise it within rap, the camp and YouTube.

\section{Juxtapositions and symbolism}

There is a juxtaposition between the sweet, upbeat chorus and the rapped verse. Symbolically the chorus represents childhood innocence and the future of the Karen; 


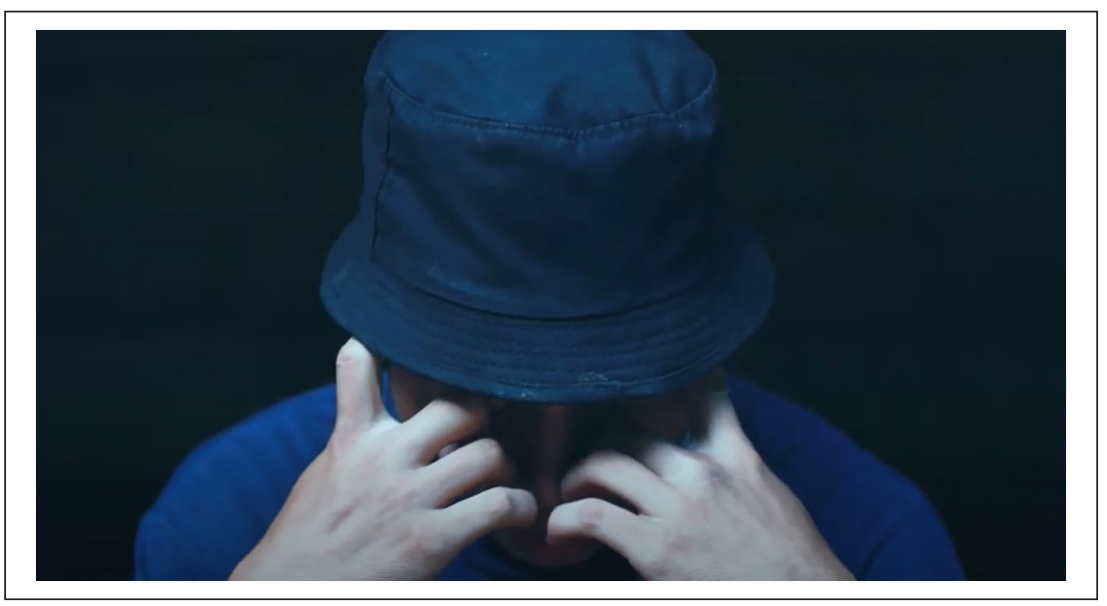

Figure 7. Disenfranchised youth.

Source: NUCELER and OBED 7, 'Life in MRM Camp'.

alternatively, the rap discusses prejudice and how Saw $\mathrm{Na}$ perceives his position as a refugee:

We need to fix these wrong views

We never dreamt of or wanted to be refugees

We want to live in our country

We want to live in our village

The accompanying music video follows a young man through the camp looking forlorn. He is often shown sitting alone or leaning against something, depicting his frustration and his powerlessness to alter his situation (Figure 7).

Referencing how some camp participants have access to technology, the man is seen sitting, holding a smartphone (Figure 8). Ironically, Saw Na says that although they may have the physical device, it is useless when the internet goes out; as MRM is one of the more remote camps along the border, the connection is often limited. When the internet is available, Saw Na uses it to connect to the broader global Karen community, many of whom were born in the camp. Nostalgic comments by Karen, who have left the camp, reminisce about their life before their resettlement, evoking childhood memories, solidarity, and belonging at a distance. Their digitally mediated presence again demonstrates two lived spaces. They are simultaneously separated physically from Saw Na yet present through their participation and comments. It is here that we can perceive how digitally mediated interactions are stretched over time and space, and how cultural, social and political identities are created and maintained from afar. 


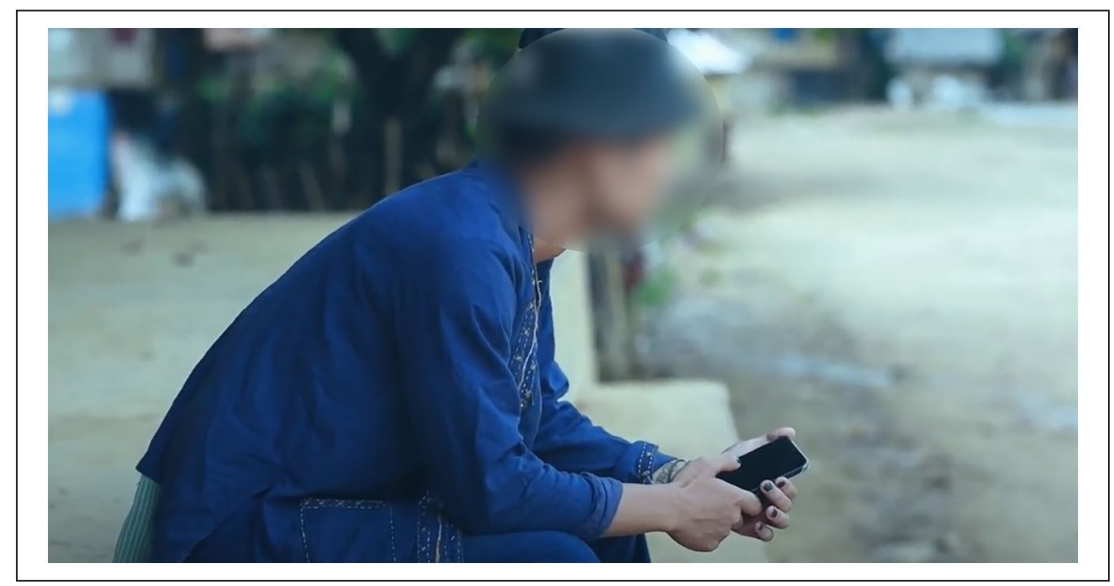

Figure 8. Smartphones in MRM.

Source: NUCELER and OBED 7, 'Life in MRM Camp'.

\section{Rapping it up}

I argue that the camps along the Thai-Myanmar border are creative, artistic and political spaces. Unlike the desperate image of the refugee camp as a bounded space of exception (Agamben, 2005), these camps are critical spaces of expression and resistance. I demonstrate through MMDA that the youths are not disconnected from Karen politics, culture and heritage, as believed by some Karen elders. Instead, I advocate that they are actively engaged participants who articulate their agency through music uploaded to YouTube.

Considering two environments simultaneously, we can explore how everyday experiences and presence offline and online converge. For my participants, whose mobility is restricted to varying degrees, YouTube provides the opportunity for transnational cultural and political flows. In 2021, as the Karen State experiences increased violence from the Tatmadaw and more Karen are displaced, we may witness louder and angrier young Karen voices demanding international recognition, an area I recommend warrants further research. Acknowledging the genderedness of this research, I propose exploration of how female Karen youths are participating and, finally, it would be of interest to compare other youth movements such as those in Palestine (Safieh, 2013), Morocco (Moussa, 2019) and Thailand (RAD, 2018), with Karen rap and YouTube.

To conclude, Karen youth have not forgotten their past. Instead, they draw from it, blending modern beats with Karen languages, cultural symbols, and traditions. More importantly, YouTube provides a space of new community, where culture evolves through global audience and participation, new music and politically charged lyrics revitalise culture and nationalism, tradition meets modernity, and, above all, YouTube as a DMS transcends time and space, and functions as a platform that encourages digitally mediated correspondence that redefines cultural, social, political, and national identities in virtual coexistence. 


\section{Funding}

The author received no financial support for the research, authorship, and/or publication of this article.

\section{Note}

1. "Burman" (or in the Burmese language Bama) are the majority population; Burmese is a more general adjective for all citizens, the majority language and the country' (South, 2011: 6).

\section{References}

Agamben G (1998) Sovereign Power and Bare Life: Homo Sacer. Stanford, CA: Stanford University Press.

Agamben G (2005) State of Exception. Chicago: University of Chicago Press.

Allman JM (ed.) (2004) Fashioning Africa: Power and the Politics of Dress - African Expressive Cultures. Bloomington, IN: Indiana University Press.

Andemicael A (2011) Positive Energy: A Review of the Role of Artistic Activities in Refugee Camps. Geneva: UNHCR, Policy Development and Evaluation Service United Nations High Commissioner for Refugees.

Anderson B (1992) Long-distance nationalism: World capitalism and the rise of identity politics. Wertheim Lecture, CASA (Centre for Asian Studies Amsterdam).

Anderson B (2006 [1983]) Imagined Communities: Reflections on the Origin and Spread of Nationalism, rev. and extended edn. London: Verso.

Baily J and Collyer M (2006) Introduction: Music and migration. Journal of Ethnic and Migration Studies 32: 167-182, https://doi.org/10.1080/13691830500487266.

Ben Moussa M (2019) Rap it up, share it up: Identity politics of youth 'social' movement in Moroccan online rap music. New Media \& Society 21: 1043-1064, https://doi. org/10.1177/1461444818821356.

boyd d (2014) It's Complicated: The Social Lives of Networked Teens. New Haven, CT: Yale University Press.

Burgess J and Green J (2009) YouTube: Online Video and Participatory Culture. Digital media and society series. Cambridge: Polity.

Cabalquinto ECB (2018) 'We're not only here but we're there in spirit': Asymmetrical mobile intimacy and the transnational Filipino family. Mobile Media \& Communication 6: 37-52, https://doi.org/10.1177/2050157917722055.

Chau C (2011) YouTube as a participatory culture. New Directions for Youth Development 2010(128): 65-74, https://doi.org/10.1002/yd.376.

Cheesman N (2002) Seeing 'Karen' in the Union of Myanmar. Asian Ethnicity 3: 199-220, https:// doi.org/10.1080/14631360220132736.

Cho V (2011) Searching for home: Explorations in new media and the Burmese diaspora in New Zealand. Pacific Journalism Review 17: 194.

Cho V (2013) Mother died and time passed: Reading diasporic identity in Karen Hta. Available at: www.poetryinternational.org/pi/cou_article/23184/Mother-died-and-time-passed/en/ nocache (accessed 17 September 2020).

Entwistle J (2015) The Fashioned Body: Fashion, Dress and Modern Social Theory. Cambridge: Polity.

Fine M (1994) Working the hyphens. In: Denzin NK and Lincoln YS (eds) Handbook of Qualitative Research. Thousand Oaks, CA: Sage, pp. 70-82.

franzke as, Bechmann A, Zimmer M, Ess CM and the Association of Internet Researchers (2020) Internet Research: Ethical Guidelines 3.0. Available at: https://aoir.org/reports/ethics3.pdf (accessed 21 Jne 2021). 
Frith S (1996) Music and identity. In: Hall S and Du Gay P (eds) Questions of Cultural Identity. London: Sage, pp. 108-128.

Gibson JJ (1979) The theory of affordances. In: The Ecological Approach to Visual Perception. New York: Psychology Press.

Gillespie M, Osseiran S and Cheesman M (2018) Syrian refugees and the digital passage to Europe: Smartphone infrastructures and affordances. Social Media + Society 4, https://doi. org/10.1177/2056305118764440.

Halpern D and Gibbs J (2013) Social media as a catalyst for online deliberation? Exploring the affordances of Facebook and YouTube for political expression. Computers in Human Behavior 29: 1159-1168.

Harriden J (2002) 'Making a name for themselves': Karen identity and the politicization of ethnicity in Burma. Journal of Burma Studies 7: 84-144.

Hermes J (2006) Citizenship in the age of the internet. European Journal of Communication 21: 295-309.

Hornig L (2019) Saw Ba U Gyi (1905-1950). Biographien Projekt Myanmar-Institute.V. Available at: http://bios.myanmar-institut.org/ (accessed 24 November 2020).

Jenkins H (2009) Confronting the Challenges of Participatory Culture: Media Education for the 21st Century. Cambridge, MA: MIT Press.

Kress G (2012) Multimodal discourse analysis. In: Gee JP and Handford M (eds) The Routledge Handbook of Discourse Analysis. Abingdon: Routledge.

Leach A (2008) 'One day it'll all make sense': Hip-hop and rap resources for music librarians. Notes 65: 9-37, https://doi.org/10.1353/not.0.0039.

Leong L (2020) Domesticating algorithms: An exploratory study of Facebook users in Myanmar. The Information Society 36: 97-108, https://doi.org/10.1080/01972243.2019.1709930.

Literat I and Kligler-Vilenchik N (2019) Youth collective political expression on social media: The role of affordances and memetic dimensions for voicing political views. New Media \& Society 21: 1988-2009.

LRWC (Lawyers' Rights Watch Canada) (2021) Myanmar: Restore elected authorities, release detainees, and protect freedoms of information, expression, and assembly. LWRC Statement, 8 February. Available at: https://www.lrwc.org/wp-content/uploads/2021/02/LRWC. Myanmar.8February2021.F.pdf (accessed 22 June 2021).

MacLachlan H (2012) Creating pan-Karen identity: The wrist tying ceremony in the United States. Asian and Pacific Migration Journal 21: 459-482, https://doi. org/10.1177/011719681202100402.

Marshall HI (1922) The Karen People of Burma: A Study in Anthropology and Ethnology. Washington, DC: Westphalia Press.

Martiniello M and Lafleur J-M (2008) Ethnic minorities' cultural and artistic practices as forms of political expression: A review of the literature and a theoretical discussion on music. Journal of Ethnic and Migration Studies 34: 1191-1215, https://doi.org/10.1080/13691830802364809.

Marwick A (2012) The public domain: Surveillance in everyday life. Surveillance \& Society 9: 378-393.

Nettl B (1983) The Study of Ethnomusicology: Thirty-one Issues and Concepts, new edn. Urbana, IL: University of Illinois Press.

NUCELER and OBED 7 (2020) Karen New Song 2020 (Life in MRM Refugee Camp). Available at: https://www.youtube.com/watch?v=1385sHoE9kw (accessed 12 October 2020).

Ong A (2006) Mutations in citizenship. Theory, Culture \& Society 23: 499-505.

RAD (Rap Against Dictatorship) (2018) Prathet Ku Mee (My country has). Available at: https:// www.youtube.com/watch?v=VZvzvLiGUtw (accessed 12 January 2020). 
Rajah A (2002) A 'nation of intent' in Burma: Karen ethno-nationalism, nationalism and narrations of nation. Pacific Review 15: 517-537, https://doi.org/10.1080/0951274021000029413.

Reilly P (2014) The 'Battle of Stokes Croft' on YouTube: The Development of an Ethical Stance for the Study of Online Comments. London: Sage.

Russell A (2011) Home, music and memory for the Congolese in Kampala. Journal of Eastern African Studies 5: 294-312, https://doi.org/10.1080/17531055.2011.571390.

Safieh R (2013) Identity, diaspora, and resistance in Palestinian hip-hop. In: Kanā‘inah M, Thorsén S-M, Bursheh H and McDonald DA (eds) Palestinian Music and Song: Expression and Resistance Since 1900. Public Cultures of the Middle East and North Africa. Bloomington, IN: Indiana University Press, pp. 69-81.

Schiller NG (2005) Long-distance nationalism. In: Ember M, Ember CR and Skoggard I (eds) Encyclopaedia of Diasporas. Boston, MA: Springer US, pp. 570-580, https://doi. org/10.1007/978-0-387-29904-4 59.

Shadrach B (2018) Upgrading Myanmar's internet access. Myanmar Times, 21 June . Available at: www.mmtimes.com/news/upgrading-myanmars-internet-access.html (accessed 12 October 2020).

Sharples R (2017) To be Karen in the Thai-Burma borderlands: Identity formation through the prism of a human rights discourse. Asian Ethnicity 18: 74-94, https://doi.org/10.1080/14631 369.2015 .1088378 .

Sheller M (2018) Theorising mobility justice. Tempo Social 30: 17-34.

Sheller M and Urry J (2000) The city and the car. International Journal of Urban and Regional Research 24: 737-757.

Slobin M (2012) The destiny of diaspora. In: Clayton M, Herbert T and Middleton R (eds) The Cultural Study of Music: A Critical Introduction. New York: Routledge, pp. 96-106.

South A (2009) Ethnic Politics in Burma. London: Routledge.

South A (2011) Burma's Longest War Anatomy of the Karen Conflict. The Netherlands: Transnational Institute (TNI).

Steuer J (1992) Defining virtual reality: Dimensions determining telepresence. Journal of Communication 42: 73-93.

Stokes M (2012) Globalization and the politics of world music. In: Clayton M, Herbert T and Middleton R (eds) The Cultural Study of Music: A Critical Introduction. New York: Routledge, pp. 107-116.

Telenor (2021) Telenor Group remains concerned with the situation in Myanmar. Available at: https://www.telenor.com/media/announcement/statement-on-the-situation-in-myanmar

Tempered Family (2020) Revolution. Available at: https://www.youtube.com/watch?v=R9OqyTq8Cw (accessed 12 October 2020).

The Border Consortium (2020) Mae Ra Moe Camp. Available at: https://www.theborderconsortium.org/where-we-work/camps-in-thailand/mae-ra-ma-luang/ (accessed 12 November 2020).

TKNG (The New Karen Generation) (2017) Who are you? Available at: https://www.youtube. com/watch?v=0UDtMjOduP8 (accessed 12 October 2020).

Twigt MA (2019) Mediated absent presence in forced displacement. Popular Communication 17: 171-184, https://doi.org/10.1080/15405702.2018.1540784.

UNHCR (UN Refugee Agency) (2020) RTG/MOI-UNHCR Verified Refugee Population (December 2020), Available at: https://www.unhcr.org/th/wp-content/uploads/sites/91/2021/01/Thailand Myanmar-Border_Refugee-Population-Overview_December-2020.pdf (accessed 23 June 2021). 
Valdovinos Kaye DB and Myint ZM (2021) Reclaiming policy in the Myanmar popular music industry. International Journal of Cultural Policy 27: 50-64, https://doi.org/10.1080/10286 632.2019.1709061.

Waters T and Philhour D (2019) Cross-national attunement to popular songs across time and place: A sociology of popular music in the United States, Germany, Thailand, and Tanzania. Social Sciences 8: 305, https://doi.org/10.3390/socsci8110305.

Zaw A (2004) Burma: Music under siege. In: Shoot the Singer! Music Censorship Today. London: Zed Books, pp. 39-61.

Zin M (2000) Karen history: In their own words. The Irrawaddy 8(10). Available at: www2. irrawaddy.com/article.php?art_id=2054 (accessed 22 June 2021).

Zin M (2002) Burmese pop music: Identity in transition. The Irrawaddy 10(7). Available at: www2.irrawaddy.com/article.php?art_id=2710 (accessed 22 June 2021).

\section{Author biography}

Charlotte Hill is a fourth-year $\mathrm{PhD}$ candidate studying at Goldsmiths, University of London, in the Department of Media, Communications and Cultural Studies. Her research explores how encamped refugees articulate their identities within the bounded physical space of a camp as well as in the lived mediated space. 